\title{
Impact of Primary Percutaneous Coronary Intervention on Complete Atrioventricular Block With Acute Inferior ST-Elevation Myocardial Infarction
}

Jahanzeb Malik ${ }^{1}$, Talha Laique ${ }^{2}$, Muhammad Hasan Farooq ${ }^{3}$, Umar Khan ${ }^{4}$, Farhan Malik ${ }^{5}$, Muhammad Zahid $^{6}$, Atif Majid ${ }^{7}$

1. Cardiology, Rawalpindi Institute of Cardiology, Rawalpindi, PAK 2. Pharmacology, Lahore Medical and Dental College, Lahore, PAK 3. Internal Medicine, Ysbyty Gwynedd Hospital, Bangor, GBR 4. Pulmonary Medicine, University Hospital Limerick, Limerick, IRL 5. Internal Medicine, Blackpool Teaching Hospitals National Health Service Foundation Trust, Blackpool, GBR 6. Family Medicine, Sherbourne Medical Center, Sherbourne, GBR 7. Paediatrics and Child Health, Aukland City Hospital, Aukland, NZL

Corresponding author: Jahanzeb Malik, heartdoc86@gmail.com

\section{Abstract}

\section{Background and aims}

Complete atrioventricular block (CAVB) is associated with poor clinical outcomes in ST-elevation myocardial infarction (STEMI). This study determined the frequency and outcomes of primary percutaneous coronary intervention (PPCI) in patients with CAVB with acute inferior STEMI.

\section{Methods}

We conducted an observational, prospective study and enrolled 151 patients who were diagnosed with inferior STEMI. All patients received PPCI. The clinical outcomes were compared in patients with and without CAVB. The data was recorded on a collection form and analyzed on Statistical Package for Social Sciences (SPSS) software. Descriptive statistics were applied. For quantitative variables, standard deviation and mean were obtained, and statistical tests were also applied.

\section{Results}

Baseline characteristics were homogeneous in all patients. Half of the study population was either diabetic or hypertensive. Out of 151 participants, 21 (13.9\%) developed CAVB. Two-thirds of the patients, who had developed heart block, reverted after PPCI. After a follow-up of two weeks, in-hospital mortality did not differ between the groups.

Received 08/13/2020

Review began $08 / 17 / 2020$ Review ended 08/17/2020 Published 08/25/2020

\section{() Copyright 2020}

Malik et al. This is an open access article distributed under the terms of the Creative Commons Attribution License CC-BY 4.0., which permits unrestricted use, distribution, and reproduction in any medium, provided the original author and source are credited.

\section{Conclusion}

We conclude that PPCI can improve outcomes of CAVB-complicated acute inferior STEMI and suggest that primary PCI should be the preferred reperfusion therapy in patients with CAVB with STEMI.

Categories: Cardiology, Healthcare Technology

Keywords: complete av block, inferior stemi, acute coronary syndrome

\section{Introduction}

Myocardial infarction (MI) can cause irreversible cell death of the heart muscle by prolonged ischemia. It occurs due to an imbalance in oxygen supply and demand owing to plaque rupture with thrombus formation in the coronary artery. The risk factors include hypertension, smoking, obesity, diabetes, and dyslipidemia [1]. The infarct depends on the artery which has been occluded. Inferior wall MI usually occurs after occlusion of the dominant right coronary artery (RCA) or left circumflex artery (LCX) [2].

Inferior infarcts are responsible for poor outcomes [3]. An inferior MI may diminish blood supply to the atrioventricular node (AV), causing a complete atrioventricular block (CAVB). In this case, it is usually temporary and typically resolves within two weeks [4]. CAVB can be preceded by hemiblocks [5].

There are some mechanisms that have been explained. AV node is supplied by the nodal branch, often arising from the right coronary artery. Severed blood supply to the node causes malfunction of the myocardial circuits, causing variable blocks. Another proposed mechanism is the high vagal tone due to the BezoldJarisch reflex [6].

In patients with acute coronary syndromes, primary percutaneous coronary intervention (PPCI) can be life- 
saving as it reduces major adverse cardiovascular events if compared with medical treatment [7]. With the advent of PPCI, the alarming incidence of CAVB is reduced [8]. CAVB, if persistent after PPCI, can be treated with a pacemaker.

The purpose of conducting the study is to determine the burden of CAVB in patients with inferior infarcts and its outcome in terms of resolution or persistence of CAVB and in-hospital mortality after primary PCI so that the patient can be managed accordingly.

\section{Materials And Methods}

This observational, prospective study was conducted at our institute for a duration of six months from January 2020 to July 2020. The sample size was calculated using the Statistical Package for Social Sciences (SPSS) software. It was found to be 151 . The sampling method was non-probability consecutive sampling.

Permission was sought from the hospital ethical committee. Written consent was taken from the patients. Particulars of all the patients who met the inclusion and exclusion criteria were recorded in the data collection form.

Patients presenting with chest pain had their electrocardiograms done. Upon meeting the criteria of inferior MI, consent for PPCI was taken and permission for enrollment in this study group was taken from the family. ST-elevation of more than $2 \mathrm{~mm}$ for males and $1.5 \mathrm{~mm}$ for females was taken as inferior MI in two or more contiguous leads (II, III, arteriovenous fistula (aVF)). Any conduction abnormality was recorded at this point in time. After primary PCI, patients were shifted to post-catheterization wards and monitored for any CAVB. Patients who did not have any conduction abnormalities were discharged after 24 hours. A temporary pacemaker was placed by a resident cardiologist during primary PCI in patients with CAVB, and they were observed for two weeks for the conduction abnormality to settle. In-hospital mortalities were included in the study.

The data collected was analyzed using IBM's Statistical Package for Social Sciences version 26. Mean and standard deviation was calculated for quantitative variables such as age and body mass index (BMI).

Frequency and percentage were calculated for qualitative variables. Stratification was used to control effect modifiers such as age, gender, and co-morbid conditions. A chi-square test was also applied, and a p-value of less than 0.05 was considered significant.

\section{Results}

This study included 151 patients with inferior myocardial infarction. The demographic details and co-morbid conditions are shown in Table 1. 


\section{Cureus}

\begin{tabular}{|l|l}
\hline Demographics and comorbid conditions & $57 \pm 11.34$ \\
\hline Age & Males: $129(85.4 \%)$ \\
Gender $(n, \%)$ & Females: $22(14.5 \%)$ \\
\hline DM (n,\%) & $73(48.3 \%)$ \\
HTN (n,\%) & $63(41.7 \%)$ \\
Smoking (n,\%) & $64(41.1 \%)$ \\
CKD (n,\%) & $5(3.3 \%)$ \\
Dyslipidemia (n, \%) & $69(45.7 \%)$ \\
CAVB & $21(13.9 \%)$ \\
CAVB resolved & $14(66.6 \%)$ \\
PPM inserted & $5(71.4 \%)$ \\
Deaths & $5(3.3 \%)$ \\
\hline
\end{tabular}

\section{TABLE 1: Demographic details, CAVB status, and Deaths}

Diabetes (DM); Hypertension (HTN); Chronic kidney disease (CKD); Complete Atrioventricular block (CAVB); Permanent Pacemaker (PPM)

There were 21 (14\%) patients who developed CAVB and 130 (86\%) patients did not. In 14 patients (66.6\%) CAVB reverted to normal sinus rhythm while five (71.4\%) patients had a permanent pacemaker inserted. There were five (3.3\%) in-hospital deaths, of which two had CAVB. None of the characteristics found was statistically significant with CAVB.

\section{Discussion}

CAVB is a known complication of acute MI. In particular, patients with inferior MI develop CAVB in increased frequency as compared with other patients. STEMI increases the risk of CAVB compared with patients with non-STEMI [9].

In this article, we studied the frequency of CAVB and its outcome after PPCI. The in-hospital mortality rates and major adverse cardiac events did not differ significantly in patients with and without CAVB. Several studies have shown that patients with inferior MI who are complicated by CAVB had an elevated risk of inhospital events $[10,11]$. In one study, CAVB significantly influenced the outcome when associated with right ventricular infarction, leading to high mortality owing to cardiomyopathy [12].

In our study, the mean age of the patients was $57 \pm 11.34$ years. Most of the patients were males (85.4\%). Seventy-three $(48.3 \%)$ of the participants were diabetic and $41.7 \%$ of the participants were hypertensive. This was relatively similar to a study that described an older population that was predominantly male [13]. In one study, the co-morbid conditions associated with poor outcomes were diabetes and hypertension [14]. This was not the case in our study.

There is a likely mechanism that has been explained for both diabetes and hypertension. Both diseases damage the blood vessels and therefore predispose patients to cardiac autonomic neuropathy [15]. Vasoconstriction in damaged vessels causes changes in the secondary messenger system which ultimately leads to fibrosis of the conducting tree. The end result is a longer refractory period within the ventricles which causes inhomogeneity of the refractory period and repolarization, leading to heart block [16].

In our setting, 21 (13.9\%) patients developed CAVB. After a primary percutaneous intervention, 14 (66.6\%) patients reverted to sinus rhythm, while seven (33.34\%) did not. This frequency of CAVB was slightly higher when compared to another study in which the frequency was $11.3 \%$ [17]. In our study, the in-hospital mortality was only $3.3 \%$, which is significantly lower than in a previous study [11].

There were several limitations to our study. This was a single-centre study with a small sample size. Extensive patient characteristics were not included and the type of pacemakers was not analyzed. Follow-up time was short and only in-hospital mortality was taken into account. The disease burden was not assessed in the patients. 


\section{Conclusions}

The incidence of the complete atrioventricular block (CAVB) complicating inferior ST-elevation myocardial infarction (STEMI) has reduced in the primary percutaneous coronary intervention (PPCI) era. In conclusion, primary PCI can ameliorate CAVB in acute inferior STEMI with an acceptable rate of in-hospital mortality. It should therefore be the primary reperfusion therapy in such patients.

\section{Additional Information \\ Disclosures}

Human subjects: Consent was obtained by all participants in this study. Research and ethics review committee - Rawalpindi Institute of Cardiology issued approval RIC/DCA/28/20. It is certified that Dr. Jahanzeb Malik had submitted a research proposal titled "Impact of Primary Percutaneous Coronary Intervention on Complete Atrio-Ventricular Dissociation With Acute Interior STEMI" for approval and acceptance. The research proposal fulfilled the National/International standards/requirements. The research and ethics review committee has no objection and therefore approved and accepted the research proposal. Animal subjects: All authors have confirmed that this study did not involve animal subjects or tissue. Conflicts of interest: In compliance with the ICMJE uniform disclosure form, all authors declare the following: Payment/services info: All authors have declared that no financial support was received from any organization for the submitted work. Financial relationships: All authors have declared that they have no financial relationships at present or within the previous three years with any organizations that might have an interest in the submitted work. Other relationships: All authors have declared that there are no other relationships or activities that could appear to have influenced the submitted work.

\section{Acknowledgements}

We would like to thank Lama for proof-reading the draft.

\section{References}

1. Vernon ST, Coffey S, D'Souza M, et al.: ST-segment-elevation myocardial infarction (STEMI) patients without standard modifiable cardiovascular risk factors-how common are they, and what are their outcomes?. J Am Heart Assoc. 2019, 8:013296. 10.1161/JAHA.119.013296

2. Huang X, Ramdhany SK, Zhang Y, Yuan Z, Mintz GS, Guo N: New ST-segment algorithms to determine culprit artery location in acute inferior myocardial infarction. Am J Emerg Med. 2016, 34:1772-1778. 10.1016/j.ajem.2016.06.005

3. Altıntaş B, Yaylak B, Ede H, et al.: Impact of right ventricular diastolic dysfunction on clinical outcomes in inferior STEMI. Herz. 2019, 44:155-160. 10.1007/s00059-017-4631-9

4. Fan X, Maharjan P, Liu P, Bai L: Effect of primary PCI on the recovery of atrioventricular block in inferior STEMI patients with late presentation (>12 hours): insights from a single center 10-year experience. J Investig Med. 2020, 68:1011-1014. 10.1136/jim-2019-001255

5. Lévy S: Bundle branch blocks and/or hemiblocks complicating acute myocardial ischemia or infarction . J Interv Card Electrophysiol. 2018, 52:287-292. 10.1007/s10840-018-0430-3

6. Chiladakis JA, Patsouras N, Manolis AS: The Bezold-Jarisch reflex in acute inferior myocardial infarction: clinical and sympathovagal spectral correlates. Clin Cardiol. 2003, 26:323-328. 10.1002/clc.4950260706

7. Regueiro A, Goicolea J, Fernández-Ortiz A, Macaya C, Sabaté M: STEMI interventions: the European perspective and stent for life initiative. Interv Cardiol Clin. 2012, 1:559-565. 10.1016/j.iccl.2012.06.008

8. Lee SN, Hwang YM, Kim GH, et al.: Primary percutaneous coronary intervention ameliorates complete atrioventricular block complicating acute inferior myocardial infarction. Clin Interv Aging. 2014, 9:20272031. 10.2147/CIA.S74088

9. Aguiar Rosa S, Timóteo AT, Ferreira L, et al.: Complete atrioventricular block in acute coronary syndrome: prevalence, characterisation and implication on outcome. Eur Heart J Acute Cardiovasc Care. 2018, 7:218223. $10.1177 / 2048872617716387$

10. Schamroth L, Ziady F, de Kock J: Acute inferior wall myocardial infarction associated with complete atrioventricular block and left posterior hemiblock. Br Heart J. 1975, 37:471-474. 10.1136/hrt.37.5.471

11. Kumar V, Sinha S, Kumar P, et al.: Short-term outcome of acute inferior wall myocardial infarction with emphasis on conduction blocks: a prospective observational study in Indian population. Anatol J Cardiol. 2017, 17:229-234. 10.14744/AnatolJCardiol.2016.6782

12. Ali H, Sarfraz S, Fawad M, Shafique Z: Frequency of right ventricular infarction in inferior wall myocardial infarction. Cureus. 2020:8238-2020. 10.7759/cureus.8238

13. Khan S, Kundi A, Sharieff S: Prevalence of right ventricular myocardial infarction in patients with acute inferior wall myocardial infarction. Int J Clin Pract. 2004, 58:354-357. 10.1111/j.1368-5031.2004.00030.x

14. Karayiannides S, Norhammar A, Frøbert O, James SK, Lagerqvist B, Lundman P: Prognosis in patients with diabetes mellitus and STEMI undergoing primary PCI. J Am Coll Cardiol. 2018, 72:1427-1428. 10.1016/j.jacc.2018.06.061

15. Bertel N, Witassek F, Puhan M, et al.: Management and outcome of patients with acute myocardial infarction presenting with pacemaker rhythm. Int J Cardiol. 2017, 230:604-609. 10.1016/j.ijcard.2016.12.047

16. Shacham Y, Leshem-Rubinow E, Steinvil A, Keren G, Roth A, Arbel Y: High degree atrioventricular block complicating acute myocardial infarction treated with primary percutaneous coronary intervention: incidence, predictors and outcomes. Isr Med Assoc J. 2015, 17:298-301. europepmc.org/article/med/26137656

17. Kim KH, Jeong MH, Ahn Y, et al.: Differential clinical implications of high-degree atrioventricular block 


\section{Cureus}

complicating ST-segment elevation myocardial infarction according to the location of infarction in the era of primary percutaneous coronary intervention. Korean Circ J. 2016, 46:315-323. 10.4070/kcj.2016.46.3.315 